\title{
Article \\ Introducing a Novel Biorelevant In Vitro Dissolution Method for the Assessment of Nicotine Release from Oral Tobacco-Derived Nicotine (OTDN) and Snus Products
}

\author{
Matthias M. Knopp ${ }^{1, *}$, Nikolai K. Kiil-Nielsen ${ }^{1}$, Anna E. Masser ${ }^{2}{ }^{\mathbb{D}}$ and Mikael Staaf ${ }^{2}$ \\ 1 Bioneer:FARMA, Department of Pharmacy, Universitetsparken 2, DK-2100 Copenhagen, Denmark; \\ nkn@bioneer.dk \\ 2 Swedish Match North Europe AB, Regulatory \& Scientific Affairs, P.O. Box 17037, S-104 62 Stockholm, \\ Sweden; anna.masser@swedishmatch.com (A.E.M.); mikael.staaf@swedishmatch.com (M.S.) \\ * Correspondence: mmk@bioneer.dk
}

check for updates

Citation: Knopp, M.M.; Kiil-Nielsen, N.K.; Masser, A.E.; Staaf, M. Introducing a Novel Biorelevant In Vitro Dissolution Method for the Assessment of Nicotine Release from Oral Tobacco-Derived Nicotine (OTDN) and Snus Products. Separations 2022, 9, 52. https:// doi.org/10.3390/separations 9020052 Academic Editor: Alena Kubatova

Received: 10 January 2022 Accepted: 13 February 2022 Published: 15 February 2022

Publisher's Note: MDPI stays neutral with regard to jurisdictional claims in published maps and institutional affiliations.

Copyright: (c) 2022 by the authors. Licensee MDPI, Basel, Switzerland. This article is an open access article distributed under the terms and conditions of the Creative Commons Attribution (CC BY) license (https:// creativecommons.org/licenses/by/ $4.0 /)$.

\begin{abstract}
The rate at which oral tobacco-derived nicotine (OTDN) and snus pouches release nicotine into saliva is crucial to determine product performance. As no standardized method is available for this purpose, this study sought to develop a biorelevant dissolution method that could both discriminate between different products and predict in vivo behavior. Using a $\mu$ DISS Profiler ${ }^{\mathrm{TM}}$ as a surrogate for the US Pharmacopoeia standard apparatuses and a custom-made sinker, nicotine release from an OTDN pouch product $\left(Z Y N^{\circledR}\right.$ Dry Smooth) and a snus product (General ${ }^{\circledR}$ Pouched Snus White Portion Large) was determined in biorelevant volumes $(10 \mathrm{~mL})$ of artificial saliva. In addition, nicotine extraction in vivo was measured for both products. Strikingly, the method showed distinct dissolution curves for OTDN and snus pouches, and the nicotine release observed in vitro did not significantly differ from the nicotine extracted in vivo. The custom-made sinker was designed to accommodate both loose and pouched oral tobacco/nicotine products, and thus the proposed in vitro dissolution method is suitable to assess nicotine release from OTDN and snus pouches. Apart from providing individual dissolution curves, the method was also able to predict in vivo nicotine extraction. Thus, this method could serve as a (biorelevant) monograph for product equivalence studies.
\end{abstract}

Keywords: oral tobacco derived nicotine (OTDN) pouches; snus; nicotine release; nicotine dissolution; nicotine extraction; equivalence

\section{Introduction}

Oral tobacco-derived nicotine (OTDN) pouch products are growing in popularity, but cigarettes remain the most common tobacco product worldwide [1]. Cigarettes are a huge health burden in terms of tobacco-related morbidity and mortality, and smoking tobacco is the factor contributing to most preventable deaths worldwide [2]. The hazards of cigarettes are a result of the inhaled combustion products formed during smoking and have less to do with their tobacco and nicotine content [3]. Still, nicotine is the addictive substance sustaining cigarette dependence. Smokeless tobacco products (STPs) expose the user to no combustion products and epidemiological data on the STP Swedish snus have shown the use of Swedish snus to be significantly less harmful, in terms of morbidity and mortality, compared to cigarettes [4-6]. Little data are available on OTDN pouches, but current literature indicate that they contain less (potentially) harmful constituents and are less toxic in vitro, compared to cigarettes $[7,8]$. OTDN pouches are therefore an enticing alternative to traditional tobacco-based products, in terms of harm reduction.

OTDN pouches come in small, white sachets that are intended to be placed between the gum and upper lip where nicotine is released into the surrounding saliva from which it permeates the buccal mucosa, and subsequently enters systemic circulation. Thus, the 
performance of these products depends on the rate at which nicotine is released. However, despite growing attention among regulatory agencies and tobacco researchers, a standardized method to evaluate the nicotine release from OTDN pouches is yet to be established.

In vitro, nicotine release can be measured by dissolution testing, a method commonly used for pharmaceuticals. Therefore, it would be logical to glance at pharmaceutical guidance's and monographs when developing a novel dissolution method. In the United States (US), STPs and OTDN pouches are regulated by the Food and Drug Administration (FDA) Center for Tobacco Products, which requires that dissolution testing is carried out on novel nicotine products as well as to demonstrate product equivalence [9].

For STPs, such as snus and moist snuff, only limited literature on development of dissolution methods that are designed to discriminate between OTDN products or simulate in vivo nicotine release is available [10-15]. One of these studies utilizing the US Pharmacopeia type 4 apparatus (USP-4) (flow-through cell) method was able to discriminate between moist snuff and OTDN pouches [15]. However, this method saw a 77\% nicotine release from a Swedish-style snus pouch after $30 \mathrm{~min}$, which greatly differs from the in vivo situation where only $31-46 \%$ nicotine extraction from the same product is reported after $1 \mathrm{~h}[13,16-18]$. As the amount of agitation on the products in the USP-4 is minimal, this inconsistency could be due to the amount of flow/volume of artificial saliva used in this method $(4 \mathrm{~mL} / \mathrm{min})$ which is almost 10 -fold higher than the unstimulated saliva flow rate $(0.5 \mathrm{~mL} / \mathrm{min})$ [19].

Other methods utilizing the USP-1 and USP-2 (basket and paddle, respectively) were able to discriminate between the dissolution curves for moist snuff and Swedish snus. The authors pointed out the benefits of using USP-1 (and USP-2) being that they are the most used apparatuses, come at a lower cost than USP-4 and their ease of use [20]. Slower rates of nicotine release were shown, although still significantly faster than in vivo, probably also due to the large amount $(500 \mathrm{~mL})$ of artificial saliva used. Moreover, it is unclear if these methods could also discriminate between moist snuff/snus and OTDN pouches.

In this study, the in vitro release of nicotine from the OTDN pouch product $Z \mathrm{ZN}^{\circledR}$ Dry Smooth and General ${ }^{\circledR}$ Pouched Snus White Portion Large (PSWL) was investigated in biorelevant volumes of artificial saliva using a $\mu$ DISS Profiler ${ }^{\mathrm{TM}}$ dissolution method. The in vitro release data (i.e., biorelevance of the proposed dissolution method) was verified through in vivo nicotine extraction studies on the same products.

\section{Materials and Methods}

\subsection{Investigational Products, Standards, and Reagents}

General PSWL is a Swedish snus product containing $8 \mathrm{mg}$ of nicotine. It comes in a rectangular pouch measuring $18 \times 33 \mathrm{~mm}$ that weighs $1.0 \mathrm{~g}$ with a moisture content of $53.5 \%$ and a $\mathrm{pH}$ of 8.7 . The pouch contains ground, air-cured tobacco, water, sodium chloride, sodium carbonate, humidifying agents, and food-grade flavorings.

ZYN Dry Smooth is an OTDN pouch product containing $6 \mathrm{mg}$ of nicotine. The pouch measures $14 \times 28 \mathrm{~mm}$, weighs $0.4 \mathrm{~g}$, contains $3 \%$ moisture, and has a $\mathrm{pH}$ of 8.3 . The pouch contains fillers (maltitol and microcrystalline cellulose), a stabilizer (hydroxypropyl cellulose), $\mathrm{pH}$ adjusters (sodium carbonate and sodium bicarbonate), nicotine salt, foodgrade flavorings, and a sweetener (acesulfame K).

Both products were provided by the manufacturer Swedish Match North Europe AB.

\subsection{Standards and Reagents}

A nicotine reference standard (>99.9\%) was sourced from Łukasiewicz IPO (Warsaw, Poland). Saliva Orthana ${ }^{\circledR}$ (artificial saliva) containing (per $100 \mathrm{~mL}$ aqueous solution): porcine gastric mucin $3500 \mathrm{mg}$, methyl-4-hydroxybenzoate $100 \mathrm{mg}$, benzalkonium chloride 2 mg, EDTA disodium salt. H2O (E386) 50 mg, H2O2 250 ppm, xylitol 2000 mg, peppermint oil 5 mg, spearmint oil 5 mg, NaCl 45 mg, KCl 63 mg, CaCl2 30 mg, K2HPO4 10 mg, KOH $76 \mathrm{mg}$ with a neutral $\mathrm{pH}$, was purchased from Biofac A/S (Kastrup, Denmark). 


\subsection{Sinker Preparation}

As there is no suitable sinker commercially available, a custom-made sinker was prepared by 3D printing a $12 \mathrm{~mm}$ tall, hollow tube with an outside diameter of $21 \mathrm{~mm}$ and a wall thickness of $2 \mathrm{~mm}$ using polylactic acid (PLA). The structure was designed by computer aided design (CAD) using the online platform Tinkercad from Autodesk (San Rafael, CA, USA), exported as .stl files and converted to a readable file for the printer using the Cura software (version 3.6.0) from Ultimaker (Geldermase, The Netherlands). An Ultimaker 3 extended from Ultimaker (Geldermalsen, The Netherlands) was used to print the tube structures from a $2.85 \mathrm{~mm}$ PLA 3D printer filament (Innofil3D BV, Emmen, Netherlands) using a printing temperature of $200{ }^{\circ} \mathrm{C}$ and a layer height of $50 \mu \mathrm{m}$. After printing, the tube was fitted with a 20 -mesh stainless steel sieve $(0.84 \mathrm{~mm}$ sieve opening) by molding it into the PLA tube at $200{ }^{\circ} \mathrm{C}$ using a hot-plate. A picture of the final product loaded with an OTDN pouch can be seen in Figure $1 \mathrm{~A}$.
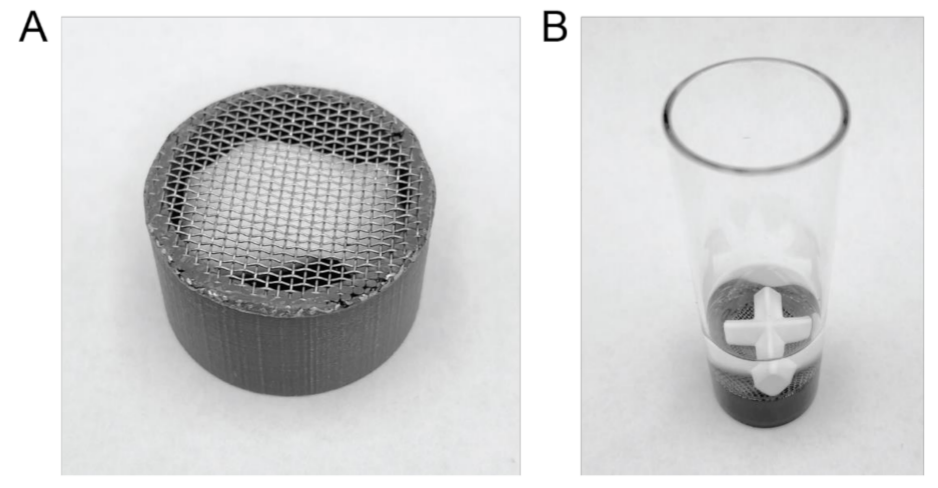

Figure 1. Details of the $\mu$ DISS Profiler ${ }^{\mathrm{TM}}$ experimental setup. (A) An OTDN pouch loaded in the custom-made sinker, 3D printed using polylactic acid (PLA) and fitted with a 20-mesh stainless steel sieve. The sinker measures $12 \mathrm{~mm}$ in height and $21 \mathrm{~mm}$ in width. (B) A snus pouch loaded in the custom-made sinker and placed on the bottom of the standard $20 \mathrm{~mL} \mu$ DISS Profiler ${ }^{\mathrm{TM}}$ dissolution vessel containing $10 \mathrm{~mL}$ of artificial saliva with a $20 \mathrm{~mm}$ cross-shaped magnetic stirrer on top.

\subsection{In Vitro Nicotine Release}

The nicotine release experiments were carried out using a $\mu$ DISS Profiler ${ }^{\mathrm{TM}}$ (Pion Inc., Billerica, MA, USA) with six channels without the in-line UV probes connected. The snus/OTDN pouches were weighed individually, loaded in the sinkers, and placed on the bottom (mesh up) of the standard $20 \mathrm{~mL}$ dissolution vessels with $20 \mathrm{~mm}$ cross-shaped magnetic stirrers on top. A picture of the experimental setup is shown in Figure 1B. The magnetic stirrers were set to operate at $100 \mathrm{rpm}$ and the minibath temperature was set to $37^{\circ} \mathrm{C}$. The experiment was initiated by addition of $10 \mathrm{~mL}$ of artificial saliva (preheated to $37^{\circ} \mathrm{C}$ ) to each of the six dissolution vessels. Samples of $250 \mu \mathrm{L}$ were taken at $\mathrm{t}=5$, $10,15,30,45,60,90$, and $120 \mathrm{~min}$ and replaced with $250 \mu \mathrm{L}$ of preheated artificial saliva. The samples were diluted immediately with $375 \mu \mathrm{L}$ acetonitrile and $375 \mu \mathrm{L}$ ethanol in a $1.5 \mathrm{~mL}$ Eppendorf centrifuge tube to precipitate proteins from the saliva and avoid potential precipitation of the nicotine upon cooling. Diluted samples were centrifuged at 10,000 rpm for $10 \mathrm{~min}$ at room temperature and the resulting supernatant was analyzed for nicotine content using high-performance liquid chromatography (HPLC). The dissolution testing was performed on 12 dosage units of each formulation in accordance with regulatory guidelines [21].

\subsection{Quantitative Analysis}

Nicotine released in vitro was quantified by HPLC-UV using an Ultimate 3000 HPLC system (Dionex, Sunnyvale, CA, USA). A reverse phase Kinetex Evo C18 100A column $(4.6 \times 100 \mathrm{~mm}, 2.6 \mu \mathrm{m})$ (Phenomenex, Værløse, Denmark) was used for the separation and the mobile phases consisted of (A) $15 \mathrm{mM}$ ammonium formate adjusted to $\mathrm{pH} 10.5$ using 
triethylamine and (B) acetonitrile, which were pumped isocratically at $75 \% \mathrm{~A}$ and $25 \% \mathrm{~B}$. A volume of $10 \mu \mathrm{L}$ was injected and eluted at a flow rate of $0.5 \mathrm{~mL} / \mathrm{min}$, and the effluent was detected at a wavelength of $260 \mathrm{~nm}$ with a retention time of approximately $4.3 \mathrm{~min}$. The concentration of nicotine in the samples was calculated using the mean value of the peak areas obtained from a calibration standard curve prepared in triplicate. Representative chromatograms are shown in Supplemental Figure S1. The method was validated for linearity, accuracy (recovery), range, precision (repeatability), limit of detection (LOD) and limit of quantification (LOQ) prior to use. The triplicate standard curve for nicotine was linear with an $\mathrm{r}^{2}=0.9998$ over the range $1.95-500 \mu \mathrm{g} / \mathrm{mL}$ and a $\mathrm{y}$-intercept at $0.86 \%$ of the target concentration response $(200 \mu \mathrm{g} / \mathrm{mL})$. At $50 \%, 100 \%$, and $150 \%$ of the target concentration response, the recovery of nicotine was $98.95-99.62 \%$. The precision of the retention time, peak area and peak height for nicotine was $0.12-0.50 \%$. The LOD and LOQ for nicotine was $0.23 \mu \mathrm{g} / \mathrm{mL}$ and $0.75 \mu \mathrm{g} / \mathrm{mL}$, respectively.

\subsection{In Vivo Nicotine Extraction}

A non-blinded, crossover, single-dose administration study was conducted to obtain the in vivo nicotine extraction data [22]. The study enrolled healthy male and female snus users aged $\geq 19$ years, willing and able to give written informed consent. The study was carried out in accordance with ethical principles that have their origin in the Declaration of Helsinki and are consistent with International Council for Harmonization (ICH)/Good Clinical Practice (GCP), European Union Clinical Trials Directive, and applicable local regulatory requirements. The study was approved by the Swedish Ethical Review Authority and registered on the ISRCTN registry (ISRCTN44913332). The 18 subjects kept the pouch still between the upper lip and gum. Each used pouch, 18 replicates per product and time point $(15$ and $60 \mathrm{~min})$, was collected and frozen $\left(-20^{\circ} \mathrm{C}\right)$ pending nicotine analysis. Unused pouches, 10 replicates per product, were collected and frozen $\left(-20{ }^{\circ} \mathrm{C}\right)$ for analysis as references in the calculations of extracted doses. The concentration of nicotine in pouches was determined using a Gas Chromatography/Mass Spectrometry (GC/MS) system (Agilent 7890A GC, 7693A autosampler and 5975C MS) using an Agilent Innowax, $60 \mathrm{~m} \times 0.25 \mathrm{~mm}$ ID column with a $0.25 \mu \mathrm{m}$ film.

\subsection{Data Analysis}

Results from the in vitro and in vivo studies are expressed as mean \pm standard deviation (SD). Statistical analysis was performed in SigmaPlot 14.0 from Systat Software Inc. (Chicago, IL, USA). A Student's t-test was performed on untransformed data to identify significant differences between in vitro and in vivo nicotine release after $15 \mathrm{~min}$ and $60 \mathrm{~min}$.

A mathematical approach recognized by the US FDA was used to compare the similarities and differences in dissolution profiles [21,23]. The difference factor $\left(f_{1}\right)$ was used to calculate the percent difference between two curves at each time point, which measures the absolute relative error between the two points. The similarity factor $\left(f_{2}\right)$ measures the similarity in the percent dissolution between two curves. The two factors were calculated using the following equations:

$$
\begin{gathered}
f_{1}=\left(\frac{\sum_{t=1}^{n}\left|R_{t}-T_{t}\right|}{\sum_{t=1}^{n} R_{t}}\right) * 100 \\
f_{2}=50 * \log \left(100 *\left(1+\frac{\sum_{t=1}^{n}\left(R_{t}-T_{t}\right)^{2}}{n}\right)^{-\frac{1}{2}}\right)
\end{gathered}
$$

$R_{t}$ and $T_{t}$ are the cumulative percentage dissolved of reference product and test product at time $t$, respectively, and $\mathrm{n}$ is the number of timepoints. Curves are considered similar for $f_{1}$ values close to 0 , and $f_{2}$ values close to 100 . Generally, dissolution profiles are judged to be equivalent if $f_{1}$ values are below 15 and if $f_{2}$ values are greater than 50 . 


\section{Results and Discussion}

Several different in vitro nicotine release methods have been proposed that are able to discriminate between different STPs, but common for these methods is that they all seem to substantially overpredict the nicotine release in vivo $[13,20]$. Therefore, this work sought to develop a discriminative and biorelevant in vitro method for nicotine release/dissolution from OTDN pouches and snus products and validate this with in vivo nicotine extraction data. To determine what volumes are biorelevant a reasoning made by the FDA in their memorandum regarding dissolution testing were followed [9]. There, usage time and salivary flow at the site where the pouch is placed were taken into consideration. No data on average usage time for ZYN Dry are available, but for pouched snus $65 \mathrm{~min}$ has been reported [24]. Both ZYN Dry and snus are placed under the upper lip where the parotid glands secrete saliva into the mouth. The resting and stimulated flow rate of saliva from the parotid glands are $0.1 \mathrm{~mL} / \mathrm{min}$ and $1.05 \mathrm{~mL} / \mathrm{min}$, respectively [25,26]. Assuming that the pouch is kept for $60 \mathrm{~min}$, the average flow of saliva from both parotid glands would vary between 6-63 mL, depending on degree of stimuli. As the pouch is kept on one side of the mouth, and therefore is mainly in contact with saliva from one of the glands, 3-33 mL can be considered biorelevant. Here, $10 \mathrm{~mL}$ of test medium was chosen, and the $\mu$ DISS Profiler ${ }^{\mathrm{TM}}$ was used as a surrogate for the USP standard dissolution apparatuses, to allow for the low volume. As there is no standard simulated saliva fluid recipe described in the US Pharmacopeia, we chose a commercially available artificial saliva as dissolution medium as opposed to less viscous buffer systems. Finally, a custom-made sinker was designed to prevent floating and pouch/material discharge during the experiments, and to accommodate both loose and pouched products (Figure 1A).

Using the novel dissolution method, nicotine release profiles for ZYN Dry Smooth and General PSWL were obtained (Figure 2). The average nicotine release profiles are plotted as percentage of dose, to account for differences in nicotine dose due to pouch filling/weight variance. After $15 \mathrm{~min}$ and $60 \mathrm{~min}$, the nicotine release from General PSWL was $9.2 \pm 4.7 \%$ and $29.9 \pm 11.2 \%$, respectively. For ZYN Dry Smooth, the nicotine release after $15 \mathrm{~min}$ and $60 \mathrm{~min}$, was $15.3 \pm 7.2 \%$ and $50.1 \pm 14.5 \%$, respectively.

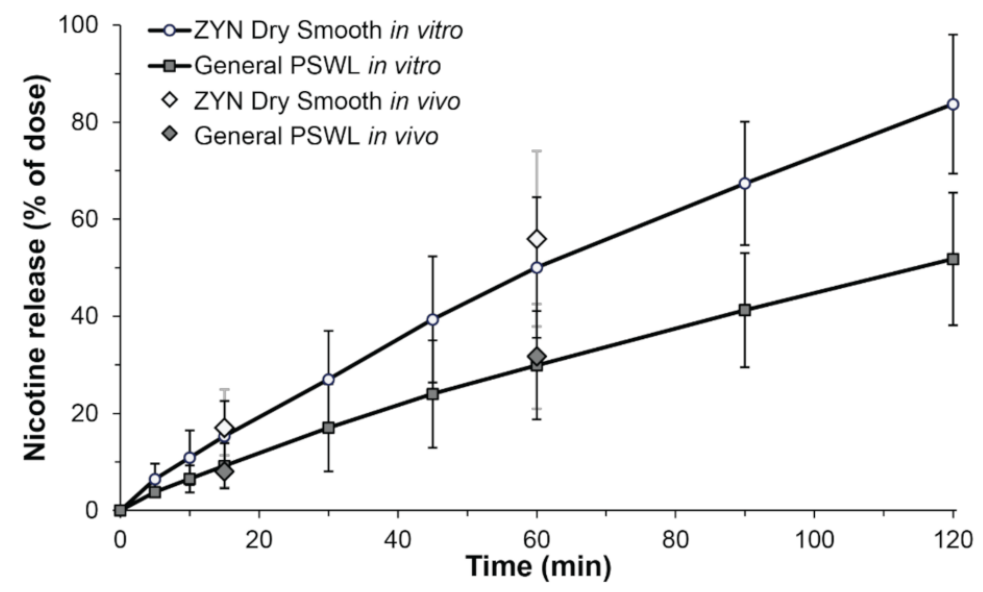

Figure 2. In vitro and in vivo nicotine release from ZYN Dry Smooth and General Pouched Snus White Portion Large (PSWL) as a function of time. Nicotine in vitro release profiles from General PSWL (dark gray squares, black error bars) and ZYN Dry Smooth (white circles, black error bars) in artificial saliva as $\%$ of dose \pm standard deviation (SD) $(n=12)$. Based on calculations of the difference $\left(f_{1}\right)$ and similarity factor $\left(f_{2}\right)$ the curves are distinct $\left(f_{1}=63.6, f_{2}=38.8\right)$. In vivo nicotine extraction after $15 \mathrm{~min}$ and $60 \mathrm{~min}$ for ZYN Dry Smooth (white diamonds, grey error bars) and General PSWL (dark grey diamonds, grey error bars) is added for comparison as \% of dose $\pm \operatorname{SD}(n=18)$. No significant differences were seen at 15 and $60 \mathrm{~min}$ between in vitro and in vivo conditions for both products, respectively. 
To investigate if the in vitro dissolution method reflected on actual in vivo conditions the results were compared to a previously conducted clinical study. The study enrolled 18 daily snus users aged $\geq 19$ years which kept one pouch at a time still between the upper lip and gum. The in vivo extracted fraction of nicotine from General PSWL, after 15 and $60 \mathrm{~min}$, was $8.0 \pm 3.3 \%$ and $31.8 \pm 10.8 \%$, respectively. For ZYN Dry Smooth, the in vivo extracted fraction of nicotine, after 15 and $60 \mathrm{~min}$, was $17.1 \pm 7.8 \%$ and $56.0 \pm 18.1 \%$, respectively (Figure 2). General PSWL contains 33\% more nicotine per pouch than ZYN Dry Smooth does. However, the absolute nicotine release was 32\% higher in ZYN Dry Smooth because of a higher extracted fraction of nicotine. The results are in line with previously published data on Swedish snus and ZYN Dry Smooth [16-18,27]. The large difference in extracted fractions between both products are likely an effect of their diverse characteristics, in terms of nicotine source (ground tobacco leaves vs. nicotine salt), moisture, $\mathrm{pH}$, and pouch geometry.

A critical feature of any dissolution method is that it should be able to distinguish between different products, here an OTDN and a snus pouch product. To compare the similarities and differences in dissolution profiles a mathematical approach recognized by the US FDA were used $[21,23]$. Based on this method, curves are considered similar for $f_{1}$ values close to 0 , and $f_{2}$ values close to 100 . In contrast, dissolution profiles are judged to be distinct if $f_{1}$ values are above 15 and if $f_{2}$ values are smaller than 50 . We obtained $f_{1}$ and $f_{2}$ values of 63.6 and 38.8, respectively, showing that the curves for ZYN Dry Smooth and General PSWL are distinct.

A second feature of dissolution testing is that it can be used to predict the in vivo behavior of a product. A Student's t-test was used to verify similarities and differences between in vitro and in vivo conditions. Strikingly, no significant differences $(p>0.05)$ were seen for both products, at the two time points tested. As earlier studies have used much higher media volumes $[13,20]$, it seems that the volume of saliva is of great importance when comparing nicotine release from OTDN and snus products.

In summary, this indicates that not only is the proposed in vitro nicotine release method able to discriminate between products from two different product categories, but it is also predictive of in vivo nicotine release, at least for the products tested. Thus, this method could serve as a predictive tool for product development and/or a monograph for oral tobacco/nicotine product equivalence studies.

\section{Conclusions}

In this work, a novel dissolution method was developed and the nicotine extraction from an OTDN pouch product (ZYN Dry Smooth) and a snus product (General PSWL) was determined. Calculations of the difference and similarity factor showed distinct nicotinerelease curves for the two different products, verifying that the method can discriminate between different product categories. To investigate if the in vitro method could predict in vivo behavior, in vivo nicotine extraction was measured for both products and both time points. No significant differences could be seen within products when comparing in vitro and in vivo data after $15 \mathrm{~min}$ and $60 \mathrm{~min}$.

Consequently, this method is to the best of our knowledge the first method developed that is both sensitive enough to discriminate between a product containing purified nicotine (ZYN Dry Smooth) and a product containing tobacco (General PSWL), as well as to be able to predict in vivo behavior.

Finally, the custom-made sinker was designed to accommodate both loose and pouched snus/snuff material. Thus, the proposed in vitro dissolution method could potentially be applied to assess the nicotine release from other oral nicotine/tobacco products e.g., moist snuff, dry snuff, and dissolvables.

Supplementary Materials: The following supporting information can be downloaded at: https: / / www.mdpi.com/article/10.3390/separations9020052/s1. 
Author Contributions: Conceptualization, M.M.K. and M.S.; methodology, M.M.K.; validation, A.E.M., N.K.K.-N., M.M.K. and M.S.; formal analysis, M.M.K. and N.K.K.-N.; writing-original draft preparation, A.E.M. and M.M.K.; writing-review and editing, A.E.M., M.M.K., M.S. and N.K.K.-N.; visualization, M.M.K. All authors have read and agreed to the published version of the manuscript.

Funding: This research received no external funding.

Institutional Review Board Statement: The study was conducted in accordance with the Declaration of Helsinki, and approved by the Swedish Ethical Review Authority (protocol code Dnr 2017/318 approved 13 September 2017).

Informed Consent Statement: Informed consent was obtained from all subjects involved in the study.

Data Availability Statement: The data presented in this study are available on request from the corresponding author. The data are not publicly available due to company policies.

Acknowledgments: The authors would like to thank R. Pendrill for valuable help with $f_{1}$ and $f_{2}$ calculations.

Conflicts of Interest: A.E.M. and M.S. are employees of Swedish Match North Europe AB who markets the ZYN and general products described in the article. M.M.K. has received funding from Swedish Match North Europe AB.

\section{References}

1. Delnevo, C.D.; Hrywna, M.; Miller Lo, E.J.; Wackowski, O.A. Examining market trends in smokeless tobacco sales in the United States: 2011-2019. Nicotine Tob. Res. 2021, 23, 1420-1424. [CrossRef]

2. The World Health Organization. WHO Global Report: Mortality Attributable to Tobacco. Available online: http://apps.who.int/ iris/bitstream/handle/10665/44815/9789241564434_eng.pdf (accessed on 2 June 2021).

3. Institute of Medicine. Clearing the Smoke: Assessing the Science Base for Tobacco Harm Reduction; The National Academies Press: Washington, DC, USA, 2001. [CrossRef]

4. Ramström, L.; Wikmans, T. Mortality attributable to tobacco among men in Sweden and other European countries: An analysis of data in a WHO report. Tob. Induc. Dis. 2014, 12, 14. [CrossRef]

5. Foulds, J.; Ramstrom, L.; Burke, M.; Fagerström, K. Effect of smokeless tobacco (snus) on smoking and public health in Sweden. Tob. Control 2003, 12, 349-359. [CrossRef]

6. Lee, P.N. Epidemiological evidence relating snus to health-An updated review based on recent publications. Harm Reduct. J. 2013, 10, 36. [CrossRef]

7. Azzopardi, D.; Liu, C.; Murphy, J. Chemical characterization of tobacco-free "modern" oral nicotine pouches and their position on the toxicant and risk continuums. Drug Chem. Toxicol. 2021, 1-9. [CrossRef]

8. Bishop, E.; East, N.; Bozhilova, S.; Santopietro, S.; Smart, D.; Taylor, M.; Meredith, S.; Baxter, A.; Breheny, D.; Thorne, D.; et al. An approach for the extract generation and toxicological assessment of tobacco-free 'modern' oral nicotine pouches. Food Chem. Toxicol. 2020, 145, 111713. [CrossRef]

9. Cecil, T.L.; Brewer, T.M.; Holman, M.; Ashley, D.L. Dissolution as a Critical Comparison of Smokeless Product Performance: SE Requirements and Recommendations for the Review of Dissolution Studies. Memorandum from Cecil. Available online: https:/ / www.fda.gov/media/124673/download (accessed on 10 September 2021).

10. Nasr, M.M.; Reepmeyer, J.C.; Tang, Y. In vitro study of nicotine release from smokeless tobacco. J. AOAC Int. 1998, 81, 540-543. [CrossRef]

11. Delvadia, P.R.; Barr, W.H.; Karnes, H.T. A biorelevant in vitro release/permeation system for oral transmucosal dosage forms. Int. J. Pharm. 2012, 430, 104-113. [CrossRef]

12. Li, P.; Zhang, J.; Sun, S.H.; Xie, J.P.; Zong, Y.L. A novel model mouth system for evaluation of In Vitro release of nicotine from moist snuff. Chem. Cent. J. 2013, 7, 176. [CrossRef] [PubMed]

13. Miller, J.H.; Danielson, T.; Pithawalla, Y.B.; Brown, A.P.; Wilkinson, C.; Wagner, K.; Aldeek, F. Method development and validation of dissolution testing for nicotine release from smokeless tobacco products using flow-through cell apparatus and UPLC-PDA. J. Chromatogr. B Anal. Technol. Biomed. Life Sci. 2020, 1141, 122012. [CrossRef]

14. Rahman, Z.; Mohamed, E.M.; Dharani, S.; Khuroo, T.; Young, M.; Feng, C.; Cecil, T.; Khan, M.A. Development and Validation of a Discriminatory Dissolution Method for Portioned Moist Snuff and Snus. J. Pharm. Sci. 2021. [CrossRef] [PubMed]

15. Aldeek, F.; McCutcheon, N.; Smith, C.; Miller, J.H.; Danielson, T.L. Dissolution Testing of Nicotine Release from OTDN Pouches: Product Characterization and Product-to-Product Comparison. Separations 2021, 8, 7. [CrossRef]

16. Lunell, E.; Fagerström, K.; Hughes, J.; Pendrill, R. Pharmacokinetic Comparison of a Novel Non-tobacco-Based Nicotine Pouch (ZYN) With Conventional, Tobacco-Based Swedish Snus and American Moist Snuff. Nicotine Tob. Res. 2020, 22, 1757-1763. [CrossRef] [PubMed] 
17. Lunell, E.; Lunell, M. Steady-state nicotine plasma levels following use of four different types of Swedish snus compared with 2-mg Nicorette chewing gum: A crossover study. Nicotine Tob. Res. 2005, 7, 397-403. [CrossRef]

18. Caraway, J.W.; Chen, P.X. Assessment of mouth-level exposure to tobacco constituents in U.S. snus consumers. Nicotine Tob. Res. 2013, 15, 670-677. [CrossRef]

19. Navazesh, M.; Christensen, C.M. A comparison of whole mouth resting and stimulated salivary measurement procedures. J. Dent. Res. 1982, 61, 1158-1162. [CrossRef]

20. Rahman, Z.; Dharani, S.; Khuroo, T.; Khan, M.A. Potential Application of USP Paddle and Basket Dissolution Methods in Discriminating for Portioned Moist Snuff and Snus Smokeless Tobacco Products. AAPS PharmSciTech 2021, 22, 51. [CrossRef]

21. Food and Drug Administration. Guidance for Industry: Dissolution Testing of Immediate Release Solid Oral Dosage Forms. Available online: https: / / www.fda.gov / regulatory-information/search-fda-guidance-documents/dissolution-testing-immediaterelease-solid-oral-dosage-forms (accessed on 10 September 2021).

22. ISRCTN44913332. The In-Vivo Extraction of Nicotine and Flavor Compounds from a Single Dose of a Non-Tobacco-Based Nicotine Pouch (ZYN®) Compared with Conventional, Tobacco-Based Swedish Snus among Current, Daily Snus Users. Available online: https: / / www.isrctn.com/ISRCTN44913332?q=\&filters=conditionCategory:Not\%20Applicable\&page=1\&pageSize=10 (accessed on 8 October 2021).

23. Moore, J.W.; Flanner, H.H. Mathematical Comparison of Curves with an Emphasis on in Vitro Dissolution Profiles. Pharm. Technol. 1996, 20, 64-74.

24. Digard, H.; Errington, G.; Richter, A.; McAdam, K. Patterns and behaviors of snus consumption in Sweden. Nicotine Tob. Res. 2009, 11, 1175-1181. [CrossRef]

25. Proctor, G.B. The physiology of salivary secretion. Periodontol 2000 2016, 70, 11-25. [CrossRef]

26. Pijpe, J.; Kalk, W.W.; Bootsma, H.; Spijkervet, F.K.; Kallenberg, C.G.; Vissink, A. Progression of salivary gland dysfunction in patients with Sjogren's syndrome. Ann. Rheum. Dis. 2007, 66, 107-112. [CrossRef]

27. Digard, H.; Gale, N.; Errington, G.; Peters, N.; McAdam, K. Multi-analyte approach for determining the extraction of tobacco constituents from pouched snus by consumers during use. Chem. Cent. J. 2013, 7, 55. [CrossRef] [PubMed] 